\title{
Fusidic Acid: A Bacterial Elongation Factor Inhibitor for the Oral Treatment of Acute and Chronic Staphylococcal Infections
}

\author{
Prabhavathi Fernandes \\ Cempra Incorporated, Chapel Hill, North Carolina 27517 \\ Correspondence: prabha@fernandes-domain.com
}

\begin{abstract}
Fusidic acid is an oral antistaphylococcal antibiotic that has been used in Europe for more than 40 years to treat skin infections as well as chronic bone and joint infections. It is a steroidal antibiotic and the only marketed member of the fusidane class. Fusidic acid inhibits protein synthesis by binding EF-G-GDP, which results in the inhibition of both peptide translocation and ribosome disassembly. It has a novel structure and novel mode of action and, therefore, there is little cross-resistance with other known antibiotics. Many mutations can occur in the FusA gene that codes for EF-G, and some of these mutations can result in high-level resistance (minimum inhibitory concentration $[\mathrm{MIC}]>64 \mathrm{mg} / \mathrm{L}$ ), whereas others result in biologically unfit staphylococci that require compensatory mutations to survive. Low-level resistance $(<8 \mathrm{mg} / \mathrm{L})$ is more common and is mediated by fusB, fus $C$, and fus $D$ genes that code for small proteins that protect EF-G-GDP from binding fusidic acid. The genes for these proteins are spread by plasmids and can be selected mostly by topical antibiotic use. Reports of resistance have led to combination use of fusidic acid with rifampin, which is superseded by the development of a new dosing regimen for fusidic acid that can be used in monotherapy. It consists of a front-loading dose to decrease the potential for resistance development followed by a maintenance dose. This dosing regimen is now being used in clinical trials in the United States for skin and refractory bone and joint infections.
\end{abstract}

$T^{\text {him }}$ he ribosome is the target for many of the commonly used natural product-derived antibiotics, such as the macrolides, tetracyclines, phenicols, and aminoglycosides, all of which inhibit protein synthesis. However, there are many other potential antibiotic targets in the protein synthesis pathway, such as the tRNA synthetases and the peptide elongation factors, elongation factor EF-Tu and EF-G (Wilson 2014). Fusidic acid, a steroidal antibiotic (Fig. 1) synthesized by the fungus Fusidium coccineum (Godtfredsen et al. 1962), is a specific inhibitor of EF-G. EF-
G performs an essential function in shifting the nascent polypeptide chain from the A site on the $30 \mathrm{~S}$ subunit to the $\mathrm{P}$ site, a process called peptide translocation, and also interacts with ribosome release factor (RRF) to release the ribosome complex on reaching the stop codon during protein synthesis (Chen et al. 2010b; Guo et al. 2012). Although there are similarities with mammalian elongation factor (EF-2), bacterial EF-G and protein synthesis, in general, are less complex than in mammalian cells, which makes EF-G a selective antibiotic target.

Editors: Lynn L. Silver and Karen Bush

Additional Perspectives on Antibiotics and Antibiotic Resistance available at www.perspectivesinmedicine.org

Copyright (C) 2016 Cold Spring Harbor Laboratory Press; all rights reserved; doi: 10.1101/cshperspect.a025437 Cite this article as Cold Spring Harb Perspect Med 2016;6:a025437 
P. Fernandes

A

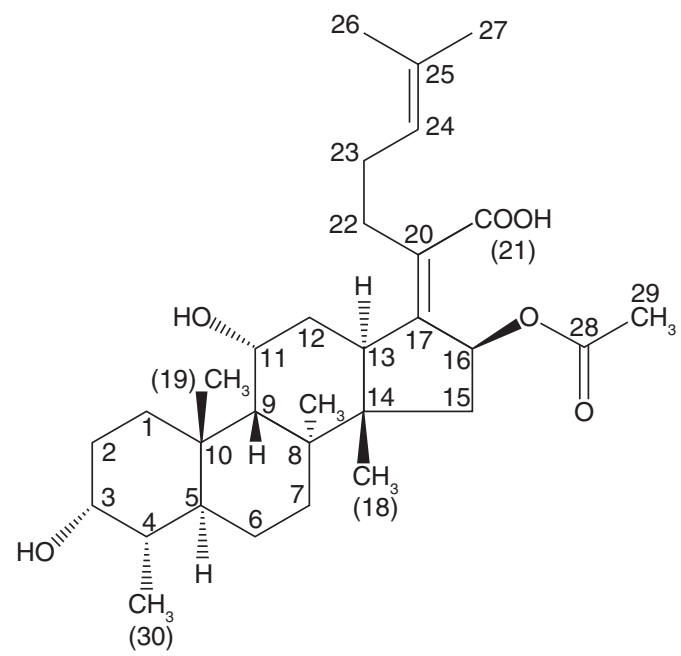

B

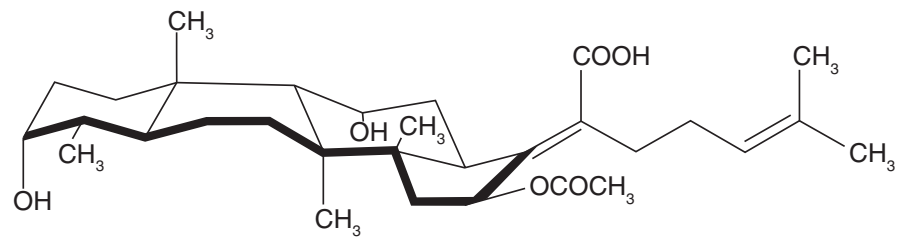

Figure 1. Structural formula of fusidic acid. (A) Steroidal conformation. (B) Chair-boat-chair conformation.

Although fusidic acid is known to be steroidal, its ring conformation is unlike that of natural steroids in that it is characterized as a chair-boat-chair conformation (Fig. 1A,B). Some of the other steroidal antibiotics include cephalosporin P1, viridian, and helvolic acid (Fig. 2A-C) (von Daehne et al. 1979; Betina 1983), but fusidic acid is the only antibiotic marketed in this class. Unlike most antibiotics, fusidic acid is not synthesized by Streptomyces spp. Another unique feature of fusidic acid is that it is not secreted into the fermentation medium after synthesis and, therefore, must be extracted from the mycelium. This makes the isolation and purification more difficult than those antibiotics that are secreted.

\section{SPECTRUM OF ACTIVITY}

After the discovery of fusidic acid in the early 1960s, its activity against a panel of bacteria was published (von Daehne et al. 1979). The results showed mostly a narrow spectrum of activity against Gram-positive bacteria, including staphylococci, and thereafter most of the subsequent studies focused on this pathogen. Following the initial discovery in 1962, it was introduced into clinical practice to treat staphylococcal skin infections (Godtfredsen et al. 1962). The in vitro evaluation of the spectrum and potency of fusidic acid against bacterial clinical isolates has been extensive (Verbist 1990) and includes studies conducted in both academic and clinical laboratories in Canada, Europe, and Australia (Collignon and Turnidge 1999; Oliva et al. 2004). Although used successfully in treating skin infections and staphylococcal bone and joint infections, the potential for the emergence of resistance during therapy has led to the use of fusidic acid in combination with rifampin (Collignon and Turnidge 1999; Howden and Grayson 2006).

Fusidic acid when formulated as sodium fusidate is well absorbed after oral administra- 


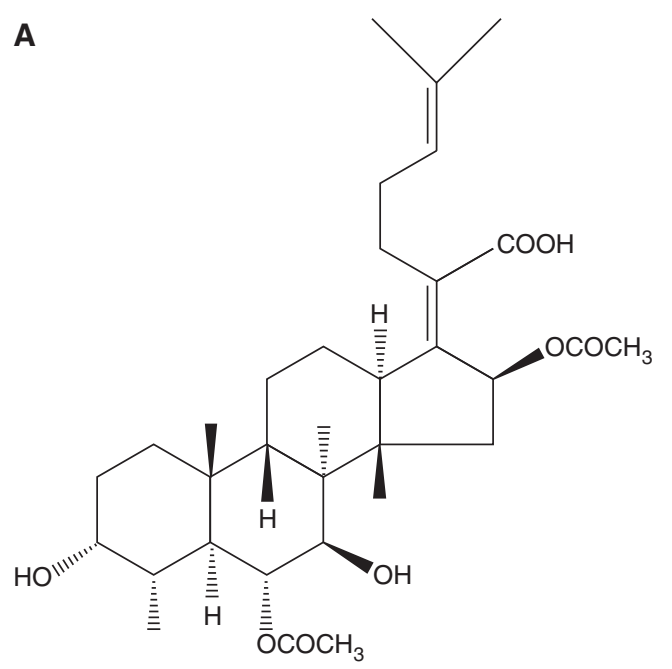

B<smiles>CO[C@H]1C(=O)c2coc3c2[C@H](c2ccc4c(c2C3=O)CCC4=O)[C@@H]1O</smiles>

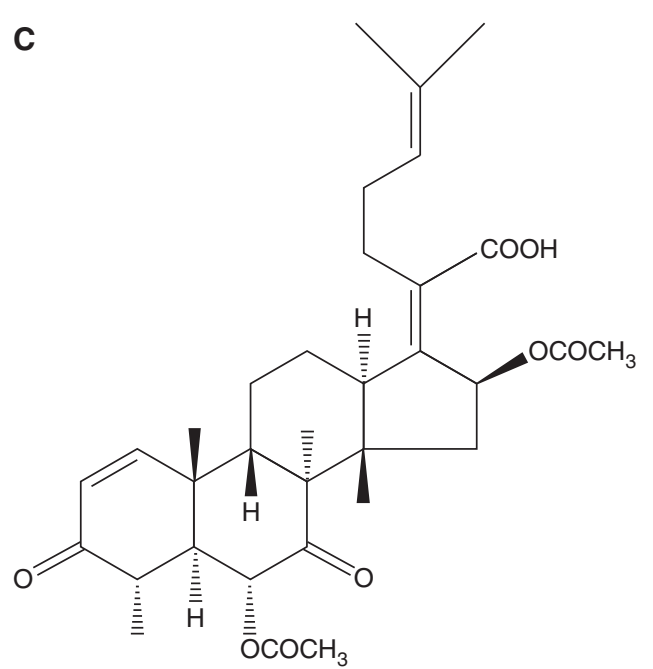

Figure 2. Structures of other steroidal antibiotics. (A) Cephalosporin P1. (B) Viridin. $(C)$ Helvolic acid.

tion, with $>90 \%$ bioavailability (Still et al. 2011). In addition, it has a long plasma halflife of $\sim 10-14 \mathrm{~h}$ and is highly ( $>95 \%$ ) but reversibly protein bound (Reeves 1987; Turnidge 1999). Attempts have been made to obtain fusidic acid analogs with improved pharmacokinetic/pharmocodynamic properties and a large number of semisynthetic analogs have been synthesized (Godtfredsen and Vangedal 1966). Some modifications were made that retain activity including saturation of the $\mathrm{C} 24-\mathrm{C} 25$ dou- ble bond, replacement of the $16 \alpha$-acetoxyl group by other groups, and conversion of the 11-hydroxyl group into the corresponding ketone. The $\mathrm{Z}$ configuration at the $\mathrm{C} 17-\mathrm{C} 20$ double bond and a $16 \beta$-acetyl group were identified as being essential for antibacterial activity. Modifications to the rings, the $\mathrm{C} 17-\mathrm{C} 20$ double bond, or functional group changes all resulted in reduced activity. Interestingly, none of the analogs are more active than fusidic acid itself. Thus, even $46 \mathrm{yr}$ after discovery, fusidic acid remains 
P. Fernandes

the only member of this class of antibiotics to be clinically useful.

As newer, more potent antistaphylococcal agents were developed and marketed, the clinical use of oral tablets of fusidic acid decreased. Furthermore, the need to administer this drug in combination with another antibiotic, such as rifampin, was not favorable owing to the potential for drug-drug interactions. However, fusidic acid as a topical ointment is broadly used in monotherapy and still has widespread use in Europe, Canada, and other parts of the world. Although marketed in Europe and Canada, fusidic acid has never received marketing approval in the United States (Fernandes and Pereira 2011). In 2007, when methicillin-resistant Staphylococcus aureus (MRSA) spread widely, there were few safe oral options for the treatment of MRSA. At this time, Cempra began development of fusidic acid for clinical use as an oral, safe alternative for the treatment of MRSA and other staphylococcal infections in the United States.

\section{PREVALENCE OF FUSIDIC ACID RESISTANT GRAM-POSITIVE BACTERIA}

Although fusidic acid is known to have a high rate of resistance, a recent study (Jones et al. 2006) showed that, in clinical strains of staphylococci from medical centers in Australia (2002-2003) that included methicillin-susceptible S. aureus (MSSA) (100 isolates) and methicillin-resistant $S$. aureus or MRSA (100 isolates), $\sim 88 \%$ and $81 \%$ were susceptible to fusidic acid, respectively, despite its use for decades in Australia. International surveillance studies conducted at Cempra from 2008 through 2011 indicated that fusidic acid had potent activity against Staphylococcus spp., including methicillin-resistant strains. It was noted in these studies that, after four decades of use in Europe, $89.3 \%$ of 2700 S. aureus strains in 2008 , $93.5 \%$ of 2166 strains in $2009,92.8 \%$ of 2263 strains in 2010, and $93.4 \%$ of 1938 strains in 2011 were susceptible to fusidic acid based on the European Committee on Antimicrobial Susceptibility Testing (EUCAST) susceptibility breakpoint of minimum inhibitory concentra- tion $(\mathrm{MIC}) \leq 1 \mathrm{mg} / \mathrm{L}$ (Jones et al. 2010a). Thus, the resistance rate was stable over many years and was $<10 \%$ in countries where the antibiotic has been used for a long time. In 2011, virtually all S. aureus strains in the United States were susceptible to fusidic acid; collectively, MSSA and MRSA strains were $99.7 \%$ susceptible. For coagulase-negative staphylococci (CoNS) collected globally in $2008-2009,75 \%-81 \%$ of strains had MIC values $\leq 1 \mathrm{mg} / \mathrm{L}$. In the same years, Streptococcus pyogenes and Streptococcus agalactiae have $\mathrm{MIC}_{90}$ values of $8 \mathrm{mg} / \mathrm{L}$ (Collignon and Turnidge 1999; Oliva et al. 2004) and resistant strains have not been reported. In the United States, the $\mathrm{MIC}_{90}$ for fusidic acid is $8 \mathrm{mg} / \mathrm{L}$ against $S$. pyogenes (Jones et al. 2011).

Although fusidic acid has moderate in vitro activity against $S$. pyogenes, it has been shown to have clinical efficacy in patients (Spelman 1999). These results can be explained by the relatively high and sustained blood levels achieved after oral dosing with fusidic acid. Plasma concentrations of $102 \mathrm{mg} / \mathrm{L}$ and mean steady-state trough concentrations of $66 \mathrm{mg} / \mathrm{L}$ have been reported following oral dosing of $500 \mathrm{mg}$ twice a day for $6 \mathrm{~d}$ (Vaillant et al. 2000; Still et al. 2011). The mean peak skin blister concentration was $79 \mathrm{mg} / \mathrm{L}$ and the steady-state mean trough skin blister concentration was $39 \mathrm{mg} / \mathrm{L}$ (Vaillant et al. 1992). The sustained blood and tissue levels along with the plasma trough levels are all above the $\mathrm{MIC}_{90}$ of fusidic acid for $S$. pyogenes. The distribution of MICs of $S$. aureus is contrasted to the narrow MIC distribution for $S$. pyogenes (or group A Streptococcus) in Figure 3. Although $S$. pyogenes is inherently less susceptible to fusidic acid than $S$. aureus $(4-8 \mathrm{mg} / \mathrm{L}$ versus $0.25 \mathrm{mg} / \mathrm{L}$, respectively), resistant strains are more often found with $S$. aureus than with $S$. pyogenes. Interestingly, fusidic acid is bactericidal for S. pyogenes (Okusanya et al. 2011; Tsuji et al.2011), although bacteriostatic for the more susceptible $S$. aureus. It is not yet known why the inhibition of EF-G in S. pyogenes results in cell death. Once the structure of $S$. pyogenes EF-G is elucidated, it could provide an explanation for these differences.

After 2010, when fusidic acid development was initiated in the United States, it was 


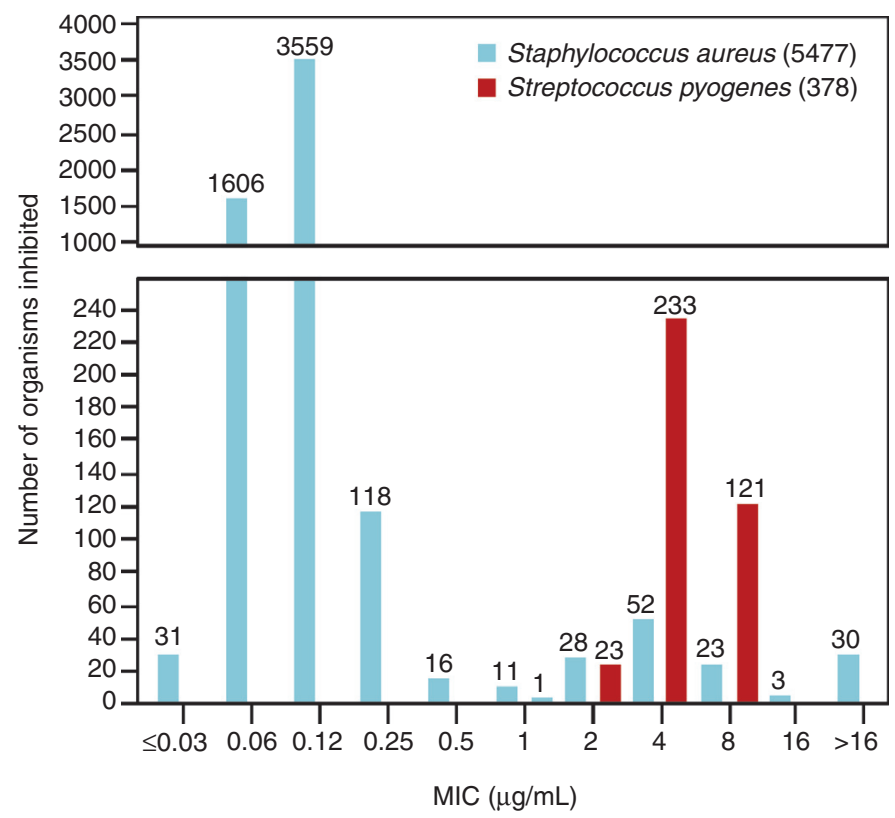

Figure 3. Minimum inhibitory concentration (MIC) distributions of fusidic acid against S. aureus (5477 strains) and S. pyogenes (378 strains). Data were obtained from an international resistance surveillance study conducted on strains collected in 2011 by Jones Microbiology Institute (North Liberty, Iowa) under contract to Cempra Inc., Chapel Hill, NC. Nonduplicated S. aureus and S. pyogenes strains were collected from 49 medical centers located in the 26 clinical laboratories in the United States and 23 clinical laboratories in Europe. Susceptibility testing was by Clinical Laboratory Standards Institute (CLSI) approved methodology by broth-dilution methods.

tested broadly against a variety of pathogens using standardized methods (Biedenbach et al. 2010). A summary of the in vitro activity from several studies is shown in Table 1. Fusidic acid is active against staphylococci and has potent activity $\left(\mathrm{MIC}_{90} 0.12 \mathrm{mg} / \mathrm{L}\right)$ against MRSA, community-acquired MRSA (CA-MRSA), such as USA300 strains, hospital-acquired MRSA (HAMRSA), and linezolid-resistant strains $\left(\mathrm{MIC}_{90}\right.$ $<0.25 \mathrm{mg} / \mathrm{L}$ ) (Sahm et al. 2013). CoNS with or without methicillin resistance, including Staphylococcus epidermidis and other species, are also susceptible to fusidic acid $\left(\mathrm{MIC}_{90} 0.25 \mathrm{mg} / \mathrm{L}\right)$ (Jones et al. 2011). Among other Gram-positive bacteria, fusidic acid has activity against enterococci $\left(\mathrm{MIC}_{90} 4 \mathrm{mg} / \mathrm{L}\right)$, Corynebacterium spp. (MICs $\leq 0.12 \mathrm{mg} / \mathrm{L}$ ), S. pyogenes $\left(\right.$ MIC $_{90}$ $8 \mathrm{mg} / \mathrm{L}$ ), and viridans streptococci (MICs 1 to $>8 \mathrm{mg} / \mathrm{L}$ ) (Biedenbach et al. 2010; Jones et al. 2011). In addition, antibacterial activity against Propionibacterium spp. has been reported with $\mathrm{MIC}_{90}$ of $1 \mathrm{mg} / \mathrm{L}$ (Hardy et al. 2014). Fusidic acid has limited activity against Gram-negative bacteria owing to its large size and lipophilicity, which does not favor transport through porins in the outer membrane of these bacteria. However, Neisseria gonorrhoeae is susceptible, with an $\mathrm{MIC}_{90}$ of $1 \mathrm{mg} / \mathrm{L}$ (Jones et al. 2010b). Fusidic acid has also shown activity against Chlamydia trachomatis $\left(\mathrm{MIC}_{90}\right.$ $0.5 \mathrm{mg} / \mathrm{L}$ ). Fusidic acid has moderate activity against some Gram-positive anaerobic bacteria, such as Clostridium species (C. difficile $\mathrm{MIC}_{90}$ $2 \mathrm{mg} / \mathrm{L}$ ) (Collignon and Turnidge 1999), and has been used to treat $C$. difficile enterocolitis (Wullt and Odenholt 2004). The unique mechanism of action of fusidic acid has limited its cross-resistance with other antibiotics and, therefore, this has not been commonly observed in clinical isolates. 
P. Fernandes

Table 1. In vitro susceptibility of fusidic acid against a wide variety of pathogens

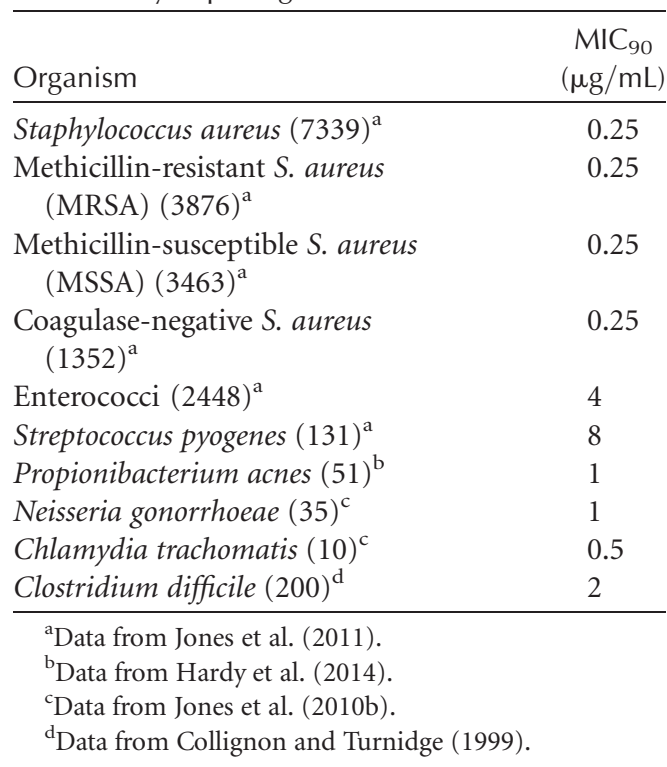

\section{pH EFFECTS AND INTRACELLULAR ACTIVITY}

Fusidic acid binds protein, primarily albumin and, therefore, the MIC is increased up to 4- to 16 -fold in the presence of $10 \%$ serum (Biedenbach et al. 2010; Lemaire et al. 2011). However, the influence of protein binding on the in vitro activity is markedly reduced at an acidic $\mathrm{pH}$. When tested at $\mathrm{pH}$ 5.5, fusidic acid activity was enhanced relative to standard in vitro testing media ( $\mathrm{pH} 7.2$ ), whereas the activity of other staphylococcal antibiotics, such as linezolid and clindamycin were either not affected or negatively impacted (Lemaire et al. 2011). The activity of fusidic acid changed from $0.25 \mathrm{mg} / \mathrm{L}$ at $\mathrm{pH} 7.2$ to $0.0058 \mathrm{mg} / \mathrm{L}$ at $\mathrm{pH} 5.5$. The MIC of linezolid remained at $2 \mathrm{mg} / \mathrm{L}$ at the acidic and neutral $\mathrm{pH}$, whereas clindamycin had decreased activity of $0.125 \mathrm{mg} / \mathrm{L}$ to $4 \mathrm{mg} / \mathrm{L}$ at $\mathrm{pH} 7.2$ (Fig. 4). Although fusidic acid has $\sim 97 \%$ protein binding, it is active in infected sites in both the skin and bone and has been able to distribute well to the dermis (Vaillant et al. 1992). Fusidic acid also penetrates macrophages and inhibits growth of staphylococci within cells. Interestingly, these studies showed that in macrophages, the intracellular concentration of fusidic acid was high (Lemaire et al. 2011). These data suggest that fusidic acid is only loosely bound to plasma protein. Thus, the in vitro activity may not accurately predict its activity at the sites of infections.

\section{MECHANISM OF PROTEIN SYNTHESIS INHIBITION}

Protein synthesis involves initiation, elongation, translocation, and release, which are catalyzed by four proteins: IF-2, EF-Tu, EF-G, and RRF. Each of these proteins possesses GTPase activity and if any of them are inhibited, protein synthesis will be blocked. Fusidic acid binds to EF-G-GDP that is bound to the ribosome and inhibits protein synthesis by inhibiting translocation of the growing polypeptide as well as the recycling of the ribosomal subunits when the stop codon on the mRNA is reached (Gao et al. 2009). In the protein synthesis cycle, the nascent growing peptide chain is bound to the $\mathrm{P}$ site of the ribosome, whereas the tRNA with a new amino acid is brought to the A site (Fig. 5). The first GTPase protein EF-Tu, brings the nascent peptide from the $\mathrm{P}$ site to the A site with the hydrolyzed GTP bound to it. The developing peptide is now attached to the new amino acid on the A site. The complex of tRNA and the newly forming peptide must move one codon on the mRNA and also transfer the tRNA-peptide to the $\mathrm{P}$ site. This process is catalyzed by EF-G-GTP in a process called translocation. Translocation of the peptide chain to the $\mathrm{P}$ site is mediated by EF-G bound to GTP, accompanied by the release of $t R N A$ from the A site. This vacates the A site to allow tRNA to bring a new amino acid to the A site and continue the cycle of peptide synthesis. The translocation step is also accompanied by the hydrolysis of EF-GGTP to form EF-G-GDP. The translocation step is strictly regulated by EF-G to ensure that there is no slippage that could result in mistranslation as the peptide chain is lengthened. Once the peptide is safely transferred to the $\mathrm{P}$ site, EF-G releases GDP and leaves the ribosome. The cycle of peptide chain synthesis and elongation continues until a stop codon on the mRNA is reached. At this time, EF-G interacts with another GTPase protein, RRF, which cata- 


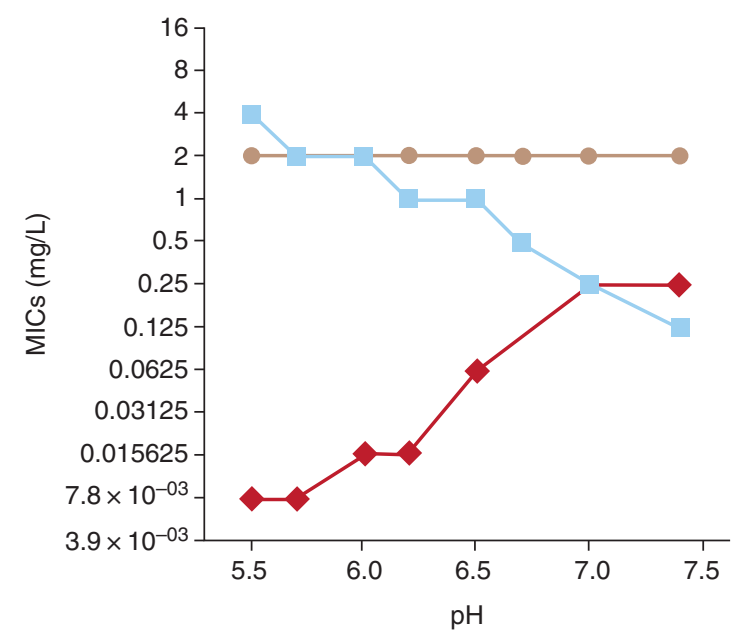

Figure 4. Influence of $\mathrm{pH}$ on the minimum inhibitory concentration (MIC) of fusidic acid, clindamycin, and linezolid.

lyzes the dissociation of the ribosomal subunits, thereby releasing the newly formed peptide and mRNA.

Fusidic acid binds to EF-G-GDP in the translocation step, which results in the EF-G's inability to release the bound GDP and in turn the EF-G-GDP complex is unable to vacate the $\mathrm{P}$ site of the ribosome (Fig. 5). Fusidic acid has little affinity for free EF-G or EF-G-GTP and allows multiple rounds of GTP hydrolysis before locking the EF-G-GDP onto the ribosome and blocking completion of translocation and

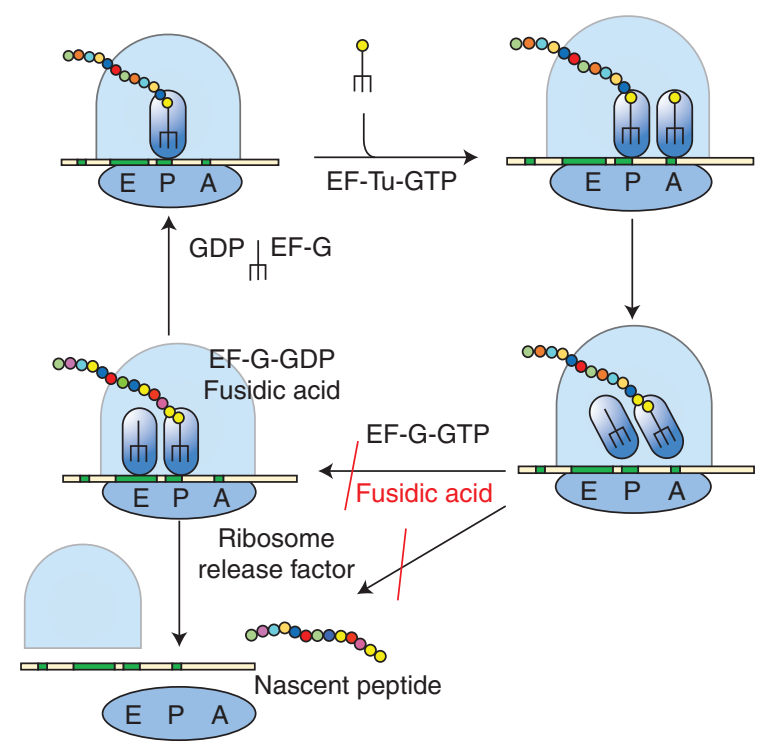

Figure 5. Cartoon demonstrating the two steps at which fusidic acid blocks peptide synthesis by binding to the EF-G-GDP complex. 
P. Fernandes

any further ribosome cycling. The $\mathrm{K}_{50}$ value for FA inhibition of the EF-G cycle was estimated at $200 \mu \mathrm{mol}$ (Borg et al. 2015). The inhibition of ribosome recycling by fusidic acid has been further characterized and shown to be a key target, as 1000 times less fusidic acid is sufficient to inhibit ribosome release versus peptide chain elongation (Savelsbergh et al. 2009). The $\mathrm{K}_{50}$ value for fusidic acid action on ribosomal recycling was calculated to be $0.1 \mu \mathrm{mol}$. The concentration of fusidic acid required to block ribosomal recycling is closer to the concentration required to inhibit $S$. aureus growth $\left(\mathrm{MIC}_{90}\right.$ $0.12 \mathrm{mg} / \mathrm{L}$ S. aureus).

Structural studies were first reported using cryoelectron microscopy of EF-G-GDP bound to the ribosome and free EF-G (Agrawal et al. 1998; Frank and Agrawal 2000; Besier et al. 2003). Further structural studies were conducted on crystal forms of Thermus thermophilus EF-G-GDP-L-9 ribosomal protein mutant-ribosome complex, which was stabilized using fusidic acid (Gao et al. 2009). Later the crystal structure of apo EF-G (free EF-G) of S. aureus (at $1.9 \AA$ ) was determined (Chen et al. 2010b; Guo et al. 2012). Although there are some differences between the EF-G of T. themophilus and that of $S$. aureus, especially in the orientation of the structures between the bound and free forms, overall, there is a general agreement that EF-G has five domains (Fig. 6A,B). As with all GTPase proteins there is a $G$ domain (domain I). In EF-G, the G domain has a P site that interacts with the $\alpha$ and $\beta$ phosphates of GTP and two switch regions that interact with the $\gamma$ phosphate. The switch regions change conformation from a tense, GTP-bound state to a relaxed GDP-bound state. The GTP-binding site and GTPase activity of EF-G are similar to other proteins that have GTPase activity, such as EF-Tu (Laurberg et al. 2000; Guo et al. 2012). The change in conformation of EF-G as GTP is hydrolyzed to GDP is also reminiscent of the change in structure observed for other GTPase proteins. In addition, the following interactions have been noted between EF-G and the ribosome based on crystallographic work and studies with mutants: domain I with the L-12 ribosomal protein; domain II with ribosomal protein S12; domains II and III with fusidic acid; domain IV with the decoding center; and domain $\mathrm{V}$ with 23S RNA as well as ribosomal protein L6. The structure of EF-G bound to the ribosome is different from that of free EF-G, with domain IV undergoing dramatic conformational change in the ribosome-bound form

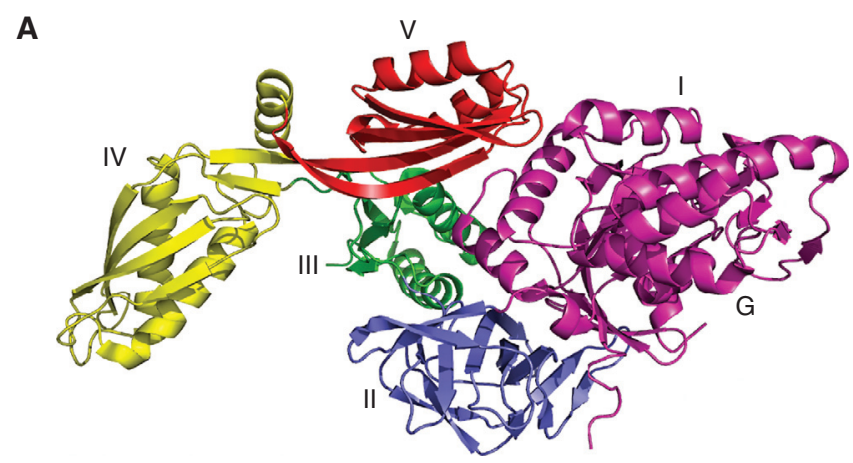

B

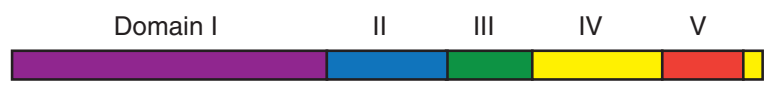

Figure 6. Structure of S. aureus EF-G. (A) Illustration of the five domains of EF-G (each shown in a different color). (B) Topology of EF-G. (From Guo et al. 2012; reproduced, with permission, from Open Biology (C) 2012 per the terms of reuse by The Royal Society Publishing open access license, rsob.royalsocietypublishing.org/ content/2/3/120016.figures-only.) 
with domains III and IV rotated relative to domains I and II. It was determined that EF-GGDP is held between the 30 S and 50S subunits. X-ray crystallography of the $T$. thermophilus cocrystals (described at $3.6 \AA$ ), shows that domain IV of EF-G is inserted into the $30 \mathrm{~S}$ decoding center. At that point, it makes contact with both the P site and mRNA, and is believed to aid in locking the translocation complex. Domain III has GTPase activity, is required for GTP hydrolysis, and makes contact with both the $30 \mathrm{~S}$ and the 50S ribosomal subunits.

The crystal structure has revealed that fusidic acid is lodged between domains II and III, surrounded by switch II near the G domain. Fusidic acid binds with high affinity only to ribosome-bound EF-G-GDP. It appears that fusidic acid cannot fit into the closed conformation structure of the switch 1 loop of EF-G when it is bound to GTP and can only bind after the switch loop opens. Once the switch loop opens, this allows water to enter and subsequently hydrolyze the GTP. Therefore, fusidic acid can only bind after GTP is hydrolyzed. Fusidic acid binds directly to domain II, stabilizing the EFG-GDP in a conformation that resembles that of EF-G-GTP instead of the normal EF-G-GDP bound form and, therefore, prevents the release of GDP. Based on this data, it has been proposed that the main mechanism of fusidic acid action is to lock the switch 2 loop in a conformation that is similar to its GTP-bound state. This causes the translocation machinery to lock into a specific conformation, thereby preventing the release of GDP from EF-G. The structure also shows that fusidic acid interacts with L11 and L12 regions of the 50 S subunit as well as domain V of EF-G.

The crystal structure data are supported by work with EF-G mutants (Hansson et al. 2005; Chen et al. 2010a). Mutant T84A, which is in the fusidic acid-binding region, displays resistance, whereas a G16V opens switch loop II and allows fusidic acid to bind, creating a hypersensitive mutant (Martemyanov et al. 2001). More than 40 EF-G mutants have been mapped and their interactions with fusidic acid have been defined. These mutants have been classified into classes $\mathrm{A}-\mathrm{D}$ and correlated to the degree of resistance based on drug binding (group A), ribosome-EF-G interactions (group B), EF-G conformation (group C), and EF-G stability (group D) (Chen et al. 2010b). Several mutations could affect more than one feature, such as conformation, and may have an impact on stability and binding.

Fusidic acid inhibits bacterial EF-G specifically and does not interact with mammalian elongation factors and other GTPase proteins. The EF-G of mitochondria was shown to be functional in Escherichia coli protein synthesis but the E. coli EF-G was not functional in mitochondrial protein synthesis (Chung and Spremulli 1990). Also, mitochondrial EF-G $\left(\mathrm{EF}-\mathrm{G}_{\mathrm{mt}}\right)$ is completely resistant to fusidic acid when tested with its mitochondrial ribosomes, but is partially active when tested with the bacterial ribosome.

\section{RESISTANCE DEVELOPMENT AND MECHANISMS}

Resistance to fusidic acid can occur by mutation of genes ( fusA) that encode the drug target EF-G as noted above, but can also occur by the acquisition of genes ( $f u s B, f u s C$ ) that encode cytoplasmic proteins that protect the target site of the drug (Castanheira et al. 2010; Pfaller et al. 2010). It can also occur rarely by a mutation in the gene fusE, which codes for a ribosomal protein. Mutation frequencies for S. aureus following a single exposure to fusidic acid at concentrations 2 to 16 times the MIC range from $10^{-6}$ to $10^{-8}$, respectively (Biedenbach et al.2010). Mutations have been reported to occur at a much lower rate in both MSSA and MRSA at therapeutic concentrations of fusidic acid, which are significantly higher than 16 times the MIC (O'Neill et al. 2001). Therefore, high plasma concentrations of fusidic acid would be expected to produce lower mutation rates in the clinical setting. Experiments conducted with therapeutically achievable plasma concentrations showed that resistance is rare when $S$. aureus strains are exposed to such concentrations (O’Neill et al. 2001).

Resistance to fusidic acid can be high-level resistance (i.e., $>64 \mathrm{mg} / \mathrm{L}$ ) or low-level 
P. Fernandes

2-32 mg/L (Castanheira et al. 2010; Jones et al. 2011). High-level resistance is attributable to mutations in the gene fusA. Mutations within the fusA gene have been identified in the laboratory to select for resistance to fusidic acid as well as in naturally occurring clinical strains. The mutations in clinical isolates include V90L, H457Q, L461K, and A655V, and some strains with single mutations like L461K can have high-level resistance $(>256 \mathrm{mg} / \mathrm{L})$. However, not all mutations in EF-G result in highlevel resistance as the actual location of the mutation in the fusidic acid-binding site of EF-G is pertinent to the specific level of resistance (Castanheira et al. 2010; Chen et al. 2010a). Mutants obtained in vitro generally have low-level resistance and can have P406L, H475Y, and R464C mutations, along with several others. In some clinical strains, more than one mutation has been identified, and some of these mutations could be compensatory through their restoration of biological fitness (Besier et al. 2005). Resistance mediated by fusA mutations that are amino acid substitutions like P406L and H457Y in EF-G show reduced growth, and biological fitness can be restored in these strains by second site mutations within EF-G, such as A67T and S416F (Nagaev et al. 2001; Besier et al. 2005; Koripella et al. 2012). The latter mutations do not contribute to resistance but rather stabilize the original mutation, which is believed to play a role in maintaining high-level resistant strains within a population. Resistance mediated by fus $A$ can be transferred to a new host by a plasmid carrying a fusA mutation (Besier et al. 2003). Compensatory mutations that can allow peptide translocation have also been described and these mutations that restore the function of EF$\mathrm{G}$ in translocation could likely bring back the balance between GTP- and GDP-bound conformations of EF-G (Johanson et al. 1996).

It is of interest that fusidic acid is less potent in vitro against $S$. pyogenes $\left(\mathrm{MIC}_{90} 4-8 \mathrm{mg} / \mathrm{L}\right.$ compared with $0.125 \mathrm{mg} / \mathrm{L}$ for $S$. aureus) but resistance to fusidic acid is not reported. The EF-G of S. pyogenes appears to be unable to mutate in either clinical situations or the laboratory setting. There is only one fusA gene in both of these species (Margus et al. 2007) and, therefore, the higher MIC but decreased resistance rate is not related to the multiplicity of fus A genes. The GTP-binding site is similar in all bacteria. It is possible that the EF-G of $S$. pyogenes has already evolved such that it renders streptococci less susceptible and further mutations could be nonviable. These mutations could result in biologically unfit strains as has been noted with some fusidic acid-resistant mutants of staphylococci. The fact that fusidic acid is bactericidal for S. pyogenes, whereas bacteriostatic for $S$. aureus also indicates additional targets that remain to be characterized in $S$. pyogenes.

Although mutations in fusA can result in high-level resistance, $f u s B, f u s C$, and fusD give rise to low-level resistance. The genes for $f u s B$, $f u s C$, and fusD code for closely related small proteins that bind to EF-G and block the binding of fusidic acid to EF-G (O'Neill and Chopra 2006). Another mechanism of resistance, which is rare but occurs in fusE, is related to frameshift or truncation of the $r p l F$ gene that codes for ribosomal protein L6 (a contact area for EF-G), resulting in low-level resistance. fus $B$ was first identified on a plasmid, pUB101, whereas fus $C$ is a chromosomally encoded homolog. The gene for $f u s B$ can be found on plasmids or on the chromosome of $S$. aureus and other staphylococcal species (O'Neill and Chopra 2006) and is transferred horizontally on a transposon-like element. This gene codes for a small EF-G-binding protein that is $\sim 25 \mathrm{kDa}$ in size. The third member of this group, fusD, confers inherent resistance among $S$. saprophyticus strains. The mechanism of a small protein blocking antibiotic-target interaction to give low-level resistance is reminiscent of the $q n r$ resistance observed in the DNA gyrase and fluoroquinolone area as well as ribosomal protection proteins $\operatorname{Tet}(\mathrm{M})$ and $\operatorname{Tet}(\mathrm{O})$ that release tetracyclines from the ribosome (Thaker et al. 2010). In the case of Qnr, the Qnr protein binds to DNA gyrase, altering its structure such that fluoroquinolones can no longer bind to the DNA-DNA gyrase complex (Tran et al. 2005). In the case of $\operatorname{Tet}(\mathrm{M})$ and $\operatorname{Tet}(\mathrm{O})$, the binding of tetracycline to the ribosome is inhibited. In both cases, the level of resistance is low yet trans- 
missible and the protein that confers such resistance binds to the target to block the activity of the antibiotic. Qnr proteins belong to a pentapeptide repeat family of proteins and differ on a structural basis from FusB.

Crystallographic analysis of FusB and FusC binding to EF-G has shown that these proteins have the same architecture and have a two-domain zinc-binding protein with a carboxy-terminal portion, which contains a fold of helices and $\beta$ sheets that make up the zinc-binding domain (Fig. 7A,B) (Gao et al. 2009; Cox et al. 2012). This zinc-binding domain interacts with high-affinity $1: 1$ with the carboxy-terminal region of EF-G. The carboxy-terminal domain of FusB has a protein fold that is not found in any other structure in the protein database (Guo et al. 2012). Because fusidic acid binds to the amino-terminal region of EF-G, steric inhibition of binding is unlikely to be the mechanism of inhibition. In addition, FusB was unable to block E. coli EF-G binding to the ribosome and is specific to the binding of the carboxy-terminal domain of EF-G of staphylococci (Guo et al.
2012). These results are explained by using hybrid protein constructs of staphylococcal and E. coli EF-G, where it was shown that the carboxy-terminal domains were different between the two organisms. Data show that FusB-type proteins dissociate the stalled ribosome-EF-GGDP complex, shifting the balance to favor dissociation, which explains the mechanism of fusidic acid resistance. A greater concentration of fusidic acid is, therefore, needed to result in fusidic acid-EF-G-GDP ribosome complexes to halt further peptide chain elongation and inhibit the growth of staphylococci carrying fusB.

FusC and FusD have $\leq 80 \%$ homology at the amino acid level with each other and with FusB (O’Neill et al. 2007). The increase in staphylococcal resistance found in regional outbreaks in Europe has been principally associated with the spread of a single fusidic acid-resistant clone, in which plasmid-borne $f u s B$ has been recruited to the $S$. aureus chromosome (O’Neill et al. 2007). S. epidermidis resistance in clinical isolates is also commonly associated with acquisition of the $f u s B$ determinant. Use of topical
A

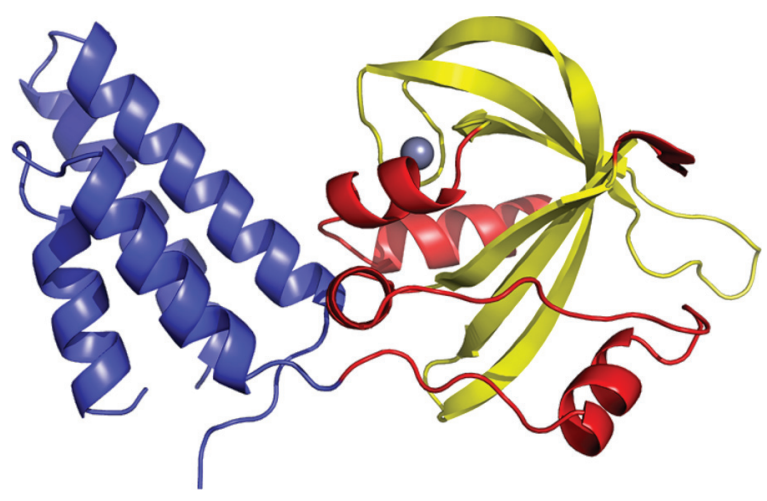

B

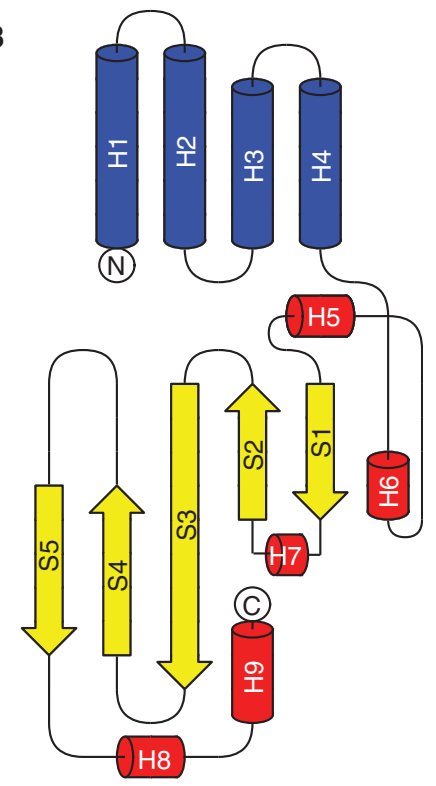

Figure 7. Structure of FusB protein showing the carboxy-terminal region that has a fold of $\alpha$ helices and $\beta$ sheets making up the zinc-binding domain. (A) Cartoon diagram of the FusB structure. (B) Domain I is shown in blue and domain II is indicated by yellow and red. (From Guo et al. 2012; reproduced, with permission, from Open Biology (C) 2012 per the terms of reuse by The Royal Society Publishing open access license, rsob .royalsocietypublishing.org/content/2/3/120016.figures-only.) 
P. Fernandes

fusidic acid is believed to enhance this resistance transfer (Dobie and Gray 2004; Williamson et al. 2014). fusB is currently the most common type of resistance in Europe and has been found in other staphylococcal species, such as $S$. aureus and Staphylococcus lugdunensis. Of 1649 S. aureus strains tested from Denmark in 2003-2005, 291 strains (17.6\%) had MICs of $>1 \mathrm{mg} / \mathrm{L}$, and $87 \%$ carried $f u s B$ and fus $C$ genes (McLaws et al. 2011). Thus, only 13\% of the strains in this collection carried fusA mutations, which confer high-level resistance. FusB protein is more efficient than FusC and FusD proteins in its ability to protect EF-G from fusidic acid binding. Unlike fusA, fusB, fusC, and $f u s D$ do not affect the fitness of the host strain and appear to be housekeeping genes. Furthermore, because they have no disadvantage to the host, they are able to survive and disseminate. It has been proposed that $f u s B$ is the ancestral gene found in Staphylococcus saprophyticus that has given rise to fusC and fusD in other staphylococcal species (O’Neill et al. 2007). At the gene level, the extent of homology is $\sim 60 \%$ among these genes and, therefore, they can be missed when tested by hybridization methods (O'Neill et al. 2007). Mutations in fus $A$ and $f u s B$ or $f u s C$ are not commonly found in the same organism (O’Neill and Chopra 2006). Corroborating this is the report from a collection of MRSA and MSSA in Taiwan. MRSA that harbored fusA did not contain $f u s B$, and MSSA with fusB did not contain fusA (Chen et al. 2010a). FusB, FusC, and FusD are thought to be accessory proteins in bacterial protein synthesis whose natural role has yet to be characterized (Cox et al. 2012). By homology, FusB is related to Listeria monocytogenes fibronectin-binding protein, but FusB does not bind fibronectin (Guo et al. 2012).

\section{NOVEL CLASS AND NOVEL STRUCTURE: IS THERE CROSS RESISTANCE?}

Although cross resistance to other classes of antibiotics is not expected because fusidic acid belongs to a unique class, such resistance has been noted in the aminoglycosides, like kanamycin (Johanson and Hughes 1994; Norstrom et al. 2007). This cross resistance is noted in small colony variants of $S$. aureus that have mutations in the structural domain V of EF-G and sometimes in domains I or III. There may also be mutations in rplF coding for ribosomal protein L6. The rplF mutant is also known as fusE. In addition, resistance owing to decreased permeability has also been reported (Collignon and Turnidge 1999), but is not likely a major mechanism of resistance.

Fusidic acid is also known for having particularly protective effects on linezolid by extending the resistance development window in S. aureus from five transfers to 25 transfers when the two antibiotics are tested in combination (Miller et al. 2008). These investigators showed that this delay in resistant mutant selection to linezolid could be through an effect on recombination as the protection was lost in recA mutants.

\section{PHARMACOKINETIC AND PHARMACODYNAMIC APPROACH TO MODIFIED DOSING OF FUSIDIC ACID TO DECREASE RESISTANCE DEVELOPMENT}

Because resistance in staphylococcal strains to fusidic acid was believed to occur rapidly, fusidic acid has been used clinically in combination with rifampin for several decades (Howden and Grayson 2006). Surprisingly, it has been noted recently that coadministration of rifampin with fusidic acid results in drug-drug interactions, presumably by the induction of the liver enzyme CYP3A4 by rifampin. These interactions subsequently caused a decrease in the blood levels of fusidic acid to sufficiently low plasma levels, allowing for possible resistance development. Even more importantly, the low fusidic acid plasma levels could result in exposure of staphylococci solely to rifampin (Oldach et al. 2015). It is well known that rifampin must only be used in combination with another antibiotic to protect it from selecting for RNA polymerase mutants. Rifampin is known to induce CYP3A4 and fusidic acid is metabolized by cytochrome P450 enzymes (Mandell 2010). Therefore, it may be deduced that rifampin induces CYP3A4 in the liver, which then metabo- 
lizes fusidic acid. As noted in an earlier section, the frequency of resistance decreases with increasing concentrations of the drug. Therefore, modern pharmacokinetic/pharmacodynamic modeling studies were pursued to determine if the dose could be adjusted to decrease resistance development such that it would allow clinical use of fusidic acid in monotherapy.

Fusidic acid has a long history of clinical use in Europe, Canada, and Australia. It has been used for staphylococcal and streptococcal skin infections with shown efficacy. Although oral tablets are used for 10-14 d for skin and soft structure infections, it has also been used safely for months to years for treating chronic bone and joint infections. In these cases, fusidic acid is often combined with rifampin (Drancourt et al. 1997; Zimmerli et al. 2004; Trampuz and Widmer 2006; Aboltins et al. 2007; Ferry et al. 2010; Chiang et al. 2011). In Europe, the current dosing regimen is $500 \mathrm{mg}$ administered three times a day, orally, which delivers high plasma concentration after a few days, but low plasma levels after the first dose. This low exposure during the first $24 \mathrm{~h}$ is likely to result in mutant selection as evidenced by the in vitro resistance development studies. As noted above, the frequency of resistance is $\sim 10^{-6}$ to $10^{-8}$ at 2 and 16 times the MIC, respectively, but resistance rates were shown to be $\geq 10^{-11}$ when the exposure to fusidic acid is higher, for example, at 15 and $30 \mathrm{mg} / \mathrm{L}$ (O'Neill et al. 2001). The pharmacokinetics (PKs) of fusidic acid in rodents is not an accurate predictor of the corresponding PK parameters in humans, as the oral bioavailability of fusidic acid in mice and rats is limited and the amount that is absorbed is rapidly excreted (Degenhardt et al. 2009). Therefore, dose optimization studies cannot be conducted using rodent models, which then led to the development of a hollow fiber infection model (HFIM) using $S$. aureus and $S$. pyogenes for optimization of the dosing regimen (Okusanya et al. 2011; Tsuji et al. 2011).

Monte Carlo simulations using human population PKs (Still et al. 2011; Tsuji et al. 2011), an in vitro pharmacodynamic infection model, and kill kinetics from the HFIM predicted the following front-loaded dosing regimens: fusidic acid dosed at either 1200 or $1500 \mathrm{mg}$ orally every $12 \mathrm{~h}$ on day 1 followed by $600 \mathrm{mg}$ every $12 \mathrm{~h}$ on subsequent days. This would likely be an effective dosing regimen for acute bacterial skin and skin structure infections (ABSSSIs) and thereby substantially reduce the emergence of resistant bacteria. Figure 8 shows the difference in plasma levels obtained from the European dosing schedule versus the new dose regimen being used in clinical trials in the United States.

A loading and maintenance dose regimen was selected from hollow fiber studies and test-

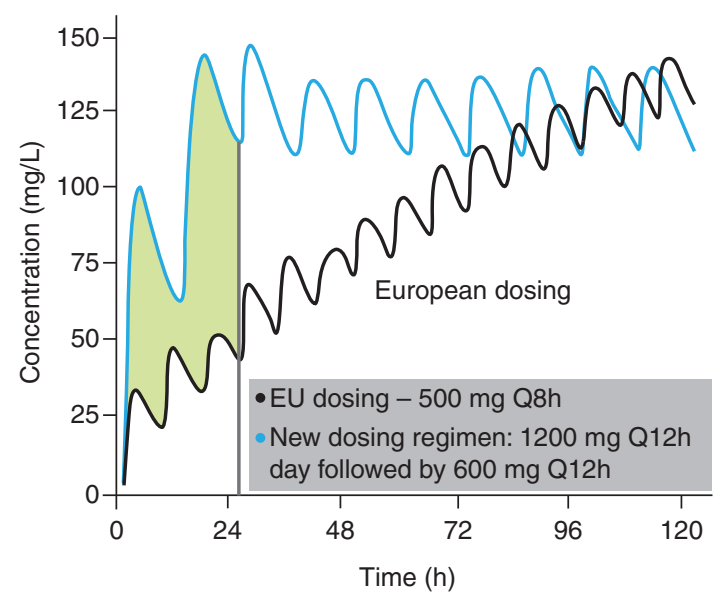

Figure 8. Plasma levels modeled from population pharmacokinetic data showing the high plasma levels achieved in the first $24 \mathrm{~h}$ for the new loading dose-maintenance dose regimen versus the European dose regimen. 
P. Fernandes

ed in a phase 2 clinical trial of ABSSSI in the United States (Craft et al. 2011). This regimen precluded the need for using rifampin or other antibiotics to help decrease resistance development. In this study, fusidic acid was tested as a loading dose and maintenance dose for $10-$ $14 \mathrm{~d}$, in which it showed comparable efficacy to linezolid. Thus, a loading dose-maintenance dose strategy has been selected to overcome resistance development in monotherapy in ABSSSI as well as in bone and joint infections (Wolfe 2011).

Fusidic acid has been used in treating chronic bone and joint infections, in which biofilm is thought to play a role in limiting antibiotic penetration. An in vitro model of biofilm was used to test fusidic acid's activity alone and in combination with traditional staphylococcal antibiotics (Siala et al. 2015). S. aureus reference strain ATCC25923 and clinical strains isolated from medical devices or from chronic tissue infections were used. Biofilms were grown for $24 \mathrm{~h}$ in 96 well plates and then exposed for $48 \mathrm{~h}$ to increasing concentrations $(0.25-64 \mathrm{mg} / \mathrm{L})$ of fusidic acid (to obtain full concentrationresponse curves), combined with concentrations corresponding to the combination drug. Combining fusidic acid with daptomycin, vancomycin, or linezolid improved its efficacy with reduction in staphylococcal viability in the biofilm model as shown in Figure 9 and appears to be a useful strategy to increase its antibacterial activity in biofilms.

Fusidic acid is active against E. coli EF-G but does not have significant activity against Gramnegative bacteria, as it is thought to be excluded by their cell membranes. The recent spread of multi-drug-resistant Gram-negative pathogens and the inability to treat these infections even with colistin has led to testing fusidic acid in combination with colistin (Phee et al. 2015). Fusidic acid is synergistic with colistin against Acinetobacter baumannii in vitro and the combination prevented resistance selection to both agents. Moreover, fusidic acid was active against A. baumannii (even when the strain was resistant to colistin), leaving the unanswered question of how this antibiotic enters the Gram-negative cell. There is one report of the successful
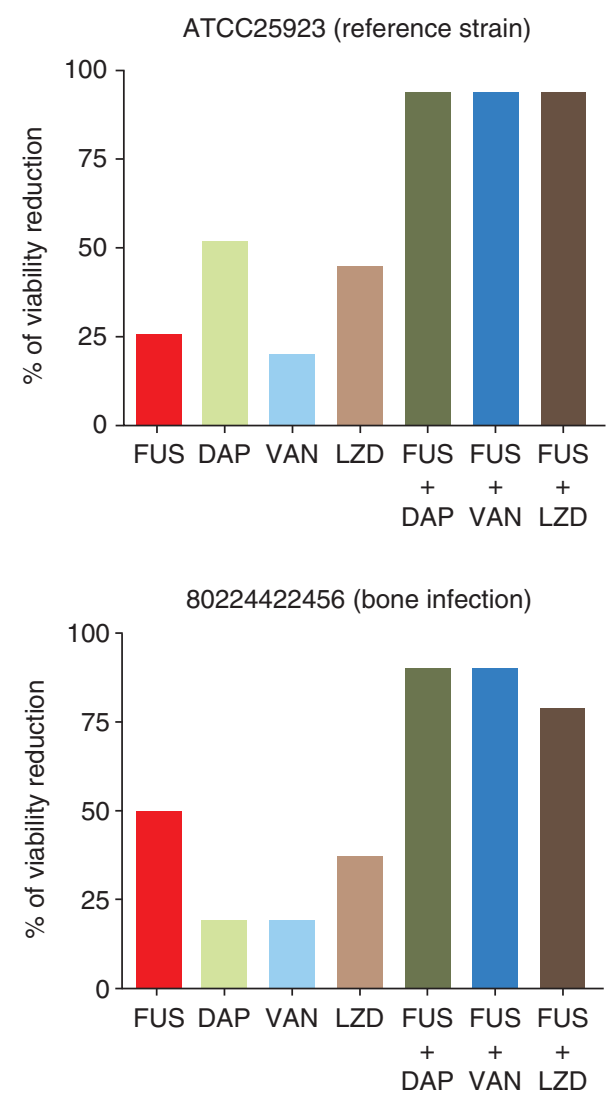

Figure 9. Percent reduction in viability of $S$. aureus within biofilms for fusidic acid, daptomycin, vancomycin, and linezolid or for fusidic acid at free drug $C_{\max }$ combined with other antibiotics. Reduction in viability was compared with the untreated control.

treatment of a patient with an infection with multidrug-resistant $A$. baumannii (Phee et al. 2014). This exciting potential for clinical use of fusidic acid will be of interest as the combination use is expanded to Gram-negative multidrug-resistant pathogens.

Fusidic acid formulated as an ointment is used more commonly than orally administered tablets. Topical use of fusidic acid is not recommended to minimize the transfer of resistance genes from commensal skin bacteria. The association between exposure to topical fusidic acid and development of resistance is attributed to the high frequency of spontaneous mutations (Mason and Howard 2004). 
Fusidic Acid: A Bacterial EF-G Inhibitor

\section{CONCLUDING REMARKS}

Antibiotics that bind to the ribosome to inhibit protein synthesis have been successfully used for treating bacterial infections. Fusidic acid has an interesting and novel mode of action in that it shows selective inhibition of EF-G in its GDP-bound state, thereby blocking both translocation and ribosome disassembly (two key steps in protein synthesis). High-level resistance is rare and the development of a new dosing regimen could decrease the risk of such resistance and the need to use fusidic acid in combination with other drugs. With the implementation of this new dosing strategy, fusidic acid could become a useful oral antistaphylococcal antibiotic for treating both complicated skin infections and chronic bone and joint infections. As shown by recent data, its use could be further expanded to include Gram-negative bacteria once the permeability hurdle is overcome with antibiotic combinations.

Structural studies on the mechanism of fusidic acid's interaction with EF-G-GDP could be useful in developing new/better fusidanes along with other molecules. In addition, revelation of common features in the structural changes in EF-G as well as EF-Tu, two GTPase proteins that function in sequence in protein synthesis, could aid in the design of inhibitors that block both these proteins. Such an inhibitor would be capable of blocking three proteins-IF-2, EF-G, and RRF-in the same pathway, increasing potency and further decreasing the likelihood of resistance development.

\section{ACKNOWLEDGMENTS}

I thank Dr. Ronald Jones, Dr. Paul Ambrose, and their teams for the design of the new dosing regimen. I also thank the staff at Cempra, Dr. Sherwood Gorbach, and Dr. Carl Craft who have helped to develop this drug in the United States. I also acknowledge the help of Dr. David Pereira for drawing the chemical structures and the support of Evan Martens, Biologist at Cempra, who has helped organize the references and has given me so much of his time to carefully edit this manuscript.

\section{REFERENCES}

Aboltins CA, Page MA, Buising KL, Jenney AW, Daffy JR, Choong PF, Stanley PA. 2007. Treatment of staphylococcal prosthetic joint infections with debridement, prosthesis retention and oral rifampicin and fusidic acid. Clin Microbiol Infect 13: 586-591.

Agrawal RK, Penczek P, Grassucci RA, Frank J. 1998. Visualization of elongation factor $\mathrm{G}$ on the Escherichia coli $70 \mathrm{~S}$ ribosome: The mechanism of translocation. Proc Natl Acad Sci 95: 6134-6138.

Besier S, Ludwig A, Brade V, Wichelhaus TA. 2003. Molecular analysis of fusidic acid resistance in Staphylococcus aureus. Mol Microbiol 47: 463-469.

Besier S, Ludwig A, Brade V, Wichelhaus TA. 2005. Compensatory adaptation to the loss of biological fitness associated with acquisition of fusidic acid resistance in Staphylococcus aureus. Antimicrob Agents Chemother 49: 1426-1431.

Betina V. 1983. Chemical classification of antibiotics. In The chemistry and biology of antibiotics (ed. Nauta WTh Rekker RF), pp. 154-156. Elsevier, Amsterdam.

Biedenbach DJ, Rhomberg PR, Mendes RE, Jones RN. 2010. Spectrum of activity, mutation rates, synergistic interactions, and the effects of $\mathrm{pH}$ and serum proteins for fusidic acid (CEM-102). Diagn Microbiol Infect Dis 66: 301-307.

Borg A, Holm M, Shiroyama I, Hauryliuk V, Pavlov M, Sanyal S, Ehrenberg M. 2015. Fusidic acid targets elongation factor $\mathrm{G}$ in several stages of translocation on the bacterial ribosome. J Biol Chem 290: 3440-3454.

Castanheira M, Watters AA, Mendes RE, Farrell DJ, Jones RN. 2010. Occurrence and molecular characterization of fusidic acid resistance mechanisms among Staphylococcus spp. from European countries (2008). J Antimicrob Chemother 65: 1353-1358.

Chen HJ, Hung WC, Tseng SP, Tsai JC, Hsueh PR, Teng LJ. 2010a. Fusidic acid resistance determinants in Staphylococcus aureus clinical isolates. Antimicrob Agents Chemother 54: 4985-4991.

Chen Y, Koripella RK, Sanyal S, Selmer M. 2010b. Staphylococcus aureus elongation factor G-structure and analysis of a target for fusidic acid. FEBS J 277: 3789-3803.

Chiang ER, Su YP, Chen TH, Chiu FY, Chen WM. 2011. Comparison of articulating and static spacers regarding infection with resistant organisms in total knee arthroplasty. Acta Orthop 82: 460-464.

Chung HK, Spremulli LL. 1990. Purification and characterization of elongation factor $\mathrm{G}$ from bovine liver mitochondria. J Biol Chem 265: 21000-21004.

Collignon P, Turnidge J. 1999. Fusidic acid in vitro activity. Int J Antimicrob Agents 12: S45-S58.

Cox G, Thompson GS, Jenkins HT, Peske F, Savelsbergh A, Rodnina MV, Wintermeyer W, Homans SW, Edwards TA, O'Neill AJ. 2012. Ribosome clearance by FusB-type proteins mediates resistance to the antibiotic fusidic acid. Proc Natl Acad Sci 109: 2102-2107.

Craft JC, Moriarty SR, Clark K, Scott D, Degenhardt TP, Still JG, Corey GR, Das A, Fernandes P. 2011. A randomized, double-blind phase 2 study comparing the efficacy and safety of an oral fusidic acid loading-dose regimen to oral 


\section{P. Fernandes}

linezolid for the treatment of acute bacterial skin and skin structure infections. Clin Infect Dis 52: S520-S526.

Degenhardt TP, Still JG, Clark K, Fernandes P. 2009. From mouse to man: The pharmacokinetics of CEM102 (fusidic acid). In 49th Interscience Conference on Antimicrobial Agents Chemotherapy, Poster A1-1930. San Francisco, CA.

Dobie D, Gray J. 2004. Fusidic acid resistance in Staphylococcus aureus. Arch Dis Child 89: 74-77.

Drancourt M, Argenson J, Roiron R, Groulier R, Raoult D. 1997. Oral treatment of Staphylococcus spp. infected orthopaedic implants with fusidic acid or ofloxacin in combination with rifampicin. J Antimicrob Chemother 39: $235-240$.

Fernandes P, Pereira D. 2011. Efforts to support the development of fusidic acid in the United States. Clin Infect Dis 52: S542-S546.

Ferry T, Uckay I, Vaudaux P, Francois P, Schrenzel J, Harbarth S, Laurent F, Bernard L, Vandenesch F, Etienne JP, et al. 2010. Risk factors for treatment failure in orthopedic device-related methicillin-resistant Staphylococcus aureus infection. Eur J Clin Microbiol Infect Dis 29: 171180.

Frank J, Agrawal RK. 2000. A ratchet-like inter-subunit reorganization of the ribosome during translocation. Nature 406: 318-322.

Gao YG, Selmer M, Dunham CM, Weixlbaumer A, Kelley AC, Ramakrishnan V. 2009. The structure of the ribosome with elongation factor $\mathrm{G}$ trapped in the posttranslocational state. Science 326: 694-699.

Godtfredsen WO, Vangedal S. 1966. On the metabolism of fusidic acid in man. Acta Chem Scand 20: 1599-1607.

Godtfredsen W, Roholt K, Tybring L. 1962. Fucidin: A new orally active antibiotic. Lancet 1: 928-931.

Guo X, Peisker K, Backbro K, Chen Y, Koripella RK, Mandava CS, Sanyal S, Selmer M. 2012. Structure and function of FusB: An elongation factor G-binding fusidic acid resistance protein active in ribosomal translocation and recycling. Open Biol 2: 120016.

Hansson S, Singh R, Gudkov AT, Liljas A, Logan DT. 2005. Structural insights into fusidic acid resistance and sensitivity in EF-G. J Mol Biol 348: 939-949.

Hardy DJ, Vicino D, Keedy K, Fernandes P. 2014. Susceptibility of Propionibacterium acnes to fusidic acid. In 54th Interscience Conference on Antimicrobial Agents Chemotherapy, Abstr. D-867.7. Washington, DC.

Howden BP, Grayson ML. 2006. Dumb and dumberThe potential waste of a useful antistaphylococcal agent: Emerging fusidic acid resistance in Staphylococcus aureus. Clin Infect Dis 42: 394-400.

Johanson U, Hughes D. 1994. Fusidic acid-resistant mutants define three regions in elongation factor G of Salmonella typhimurium. Gene 143: 55-59.

Johanson U, Aevarsson A, Liljas A, Hughes D. 1996. The dynamic structure of EF-G studied by fusidic acid resistance and internal revertants. J Mol Biol 258: 420-432.

Jones RN, Li Q, Kohut B, Biedenbach DJ, Bell J, Turnidge JD. 2006. Contemporary antimicrobial activity of triple antibiotic ointment: A multiphased study of recent clinical isolates in the United States and Australia. Diagn Microbiol Infect Dis 54: 63-71.
Jones RN, Castanheira M, Rhomberg PR, Woosley LN, Pfaller MA. 2010a. Performance of fusidic acid (CEM-102) susceptibility testing reagents: Broth microdilution, disk diffusion, and Etest methods as applied to Staphylococcus aureus. J Clin Microbiol 48: 972-976.

Jones RN, Biedenbach DJ, Roblin PM, Kohlhoff SA, Hammerschlag MR. 2010b. Update on fusidic acid (CEM102) tested against Neisseria gonorrhoeae and Chlamydia trachomatis. Antimicrob Agents Chemother 54: 45184519.

Jones RN, Mendes RE, Sader HS, Castanheira M. 2011. In vitro antimicrobial findings for fusidic acid tested against contemporary (2008-2009) Gram-positive organisms collected in the United States. Clin Infect Dis 52: S477S486.

Koripella RK, Chen Y, Peisker K, Koh CS, Selmer M, Sanyal S. 2012. Mechanism of elongation factor-G-mediated fusidic acid resistance and fitness compensation in Staphylococcus aureus. J Biol Chem 287: 30257-30267.

Laurberg M, Kristensen O, Martemyanov K, Gudkov AT, Nagaev I, Hughes D, Liljas A. 2000. Structure of a mutant EF-G reveals domain III and possibly the fusidic acid binding site. J Mol Biol 303: 593-603.

Lemaire S, Van Bambeke F, Pierard D, Appelbaum PC, Tulkens PM. 2011. Activity of fusidic acid against extracellular and intracellular Staphylococcus aureus: Influence of $\mathrm{pH}$ and comparison with linezolid and clindamycin. Clin Infect Dis 52: S493-S503.

Mandell LA. 2010. Fusidic acid. In Principles and practice of infectious diseases (ed. Mandell GL, et al.), pp. 355-357. Churchill Livingstone, Philadelphia.

Margus T, Remm M, Tenson T. 2007. Phylogenetic distribution of translational GTPases in bacteria. BMC Genomics 8: 15 .

Martemyanov KA, Liljas A, Yarunin AS, Gudkov AT. 2001. Mutations in the G-domain of elongation factor $\mathrm{G}$ from Thermus thermophilus affect both its interaction with GTP and fusidic acid. J Biol Chem 276: 28774-28778.

Mason BW, Howard AJ. 2004. Fusidic acid resistance in community isolates of methicillin susceptible Staphylococcus aureus and the use of topical fusidic acid: A retrospective case-control study. Int J Antimicrob Agents 23: 300-303.

McLaws FB, Larsen AR, Skov RL, Chopra I, O’Neill AJ. 2011. Distribution of fusidic acid resistance determinants in methicillin-resistant Staphylococcus aureus. Antimicrob Agents Chemother 55: 1173-1176.

Miller K, O’Neill AJ, Wilcox MH, Ingham E, Chopra I. 2008. Delayed development of linezolid resistance in Staphylococcus aureus following exposure to low levels of antimicrobial agents. Antimicrob Agents Chemother 52: 1940 1944.

Nagaev I, Bjorkman J, Andersson DI, Hughes D. 2001. Biological cost and compensatory evolution in fusidic acidresistant Staphylococcus aureus. Mol Microbiol 40: 433439.

Norstrom T, Lannergard J, Hughes D. 2007. Genetic and phenotypic identification of fusidic acid-resistant mutants with the small-colony-variant phenotype in Staphylococcus aureus. Antimicrob Agents Chemother 51: 4438-4446. 
Okusanya OO, Tsuji BT, Bulitta JB, Forrest A, Bulik CC, Bhavnani SM, Fernandes P, Ambrose PG. 2011. Evaluation of the pharmacokinetics-pharmacodynamics of fusidic acid against Staphylococcus aureus and Streptococcus pyogenes using in vitro infection models: Implications for dose selection. Diagn Microbiol Infect Dis 70: 101-111.

Oldach D, Stolarski E, Murphy B, Mould D, Das A, Fernandes P. 2015. Rifampin (RIF) significantly reduces plasma concentrations of fusidic acid (FA) when used in combination for treatment of prosthetic joint infection (PJI). In 25th European Congress of Clinical Microbiology and Infectious Diseases, Poster 2352. Copenhagen, Denmark.

Oliva B, O’Neill AJ, Miller K, Stubbings W, Chopra I. 2004. Anti-staphylococcal activity and mode of action of clofazimine. J Antimicrob Chemother 53: 435-440.

O’Neill AJ, Chopra I. 2006. Molecular basis of fusB-mediated resistance to fusidic acid in Staphylococcus aureus. Mol Microbiol 59: 664-676.

O’Neill AJ, Cove JH, Chopra I. 2001. Mutation frequencies for resistance to fusidic acid and rifampicin in Staphylococcus aureus. J Antimicrob Chemother 47: 647-650.

O'Neill AJ, Larsen AR, Skov R, Henriksen AS, Chopra I. 2007. Characterization of the epidemic European fusidic acid-resistant impetigo clone of Staphylococcus aureus. J Clin Microbiol 45: 1505-1510.

Pfaller MA, Castanheira M, Sader HS, Jones RN. 2010. Evaluation of the activity of fusidic acid tested against contemporary Gram-positive clinical isolates from the USA and Canada. Int J Antimicrob Agents 35: 282-287.

Phee L, BB, Wareham DW. 2014. Successful treatment of multi-drug resistant Acinetobacter baumannii ventilatorassociated pneumonia with a novel colistin and fusidic acid combination therapy. In ID Week, Poster 481. Philadelphia, PA.

Phee LM, Betts JW, Bharathan B, Wareham DW. 2015. Colistin and fusidic acid: A novel potent synergistic combination for the treatment of multi-drug resistant Acinetobacter baumannii infections. Antimicrob Agents Chemother 59: 4544-4550.

Reeves DS. 1987. The pharmacokinetics of fusidic acid. $J$ Antimicrob Chemother 20: 467-476.

Sahm DF, Deane J, Pillar CM, Fernandes P. 2013. In vitro activity of CEM-102 (fusidic acid) against prevalent clones and resistant phenotypes of Staphylococcus aureus. Antimicrob Agents Chemother 57: 4535-4536.

Savelsbergh A, Rodnina MV, Wintermeyer W. 2009. Distinct functions of elongation factor $\mathrm{G}$ in ribosome recycling and translocation. RNA 15: 772-780.

Siala W, R-V H, Fernandes P, Tulkens PM, Van Bambeke F. 2015. Activity of fusidic acid (FUS) alone or in combination with daptomycin (DAP), vancomycin (VAN), or linezolid (LZD) in an in vitro model of Staphylococcus aureus biofilm. In the 25th European Congress on Clinical Microbiology and Infectious Diseases, Abstr. EV0056. Copenhagen, Denmark.
Spelman D. 1999. Fusidic acid in skin and soft tissue infections. Int J Antimicrob Agents 12: S59-S66.

Still JG, Clark K, Degenhardt TP, Scott D, Fernandes P, Gutierrez MJ. 2011. Pharmacokinetics and safety of single multiple, and loading doses of fusidic acid in healthy subjects. Clin Infect Dis 52: S504-S512.

Thaker M, Spanogiannopoulos P, Wright GD. 2010. The tetracycline resistome. Cell Mol Life Sci 67: 419-431.

Trampuz A, Widmer AF. 2006. Infections associated with orthopedic implants. Curr Opin Infect Dis 19: 349-356.

Tran JH, Jacoby GA, Hooper DC. 2005. Interaction of the plasmid-encoded quinolone resistance protein Qnr with Escherichia coli DNA gyrase. Antimicrob Agents Chemother 49: $118-125$.

Tsuji BT, Okusanya OO, Bulitta JB, Forrest A, Bhavnani SM, Fernandez PB, Ambrose PG. 2011. Application of pharmacokinetic-pharmacodynamic modeling and the justification of a novel fusidic acid dosing regimen: Raising Lazarus from the dead. Clin Infect Dis 52: S513-S519.

Turnidge J. 1999. Fusidic acid pharmacology, pharmacokinetics and pharmacodynamics. Int J Antimicrob Agents 12: S23-S34.

Vaillant L, Machet L, Taburet AM, Sorensen H, Lorette G. 1992. Levels of fusidic acid in skin blister fluid and serum after repeated administration of two dosages (250 and 500 mg). Br J Dermatol 126: 591-595.

Vaillant L, Le Guellec C, Jehl F, Barruet R, Sorensen H, Roiron R, Autret-Leca E, Lorette G. 2000. Comparative diffusion of fusidic acid, oxacillin, and pristinamycin in dermal interstitial fluid after repeated oral administration. Ann Dermatol Venereol 127: 33-39.

Verbist L. 1990. The antimicrobial activity of fusidic acid. J Antimicrob Chemother 25: 1-5.

von Daehne W, Godtfredsen WO, Rasmussen PR. 1979. Structure-activity relationships in fusidic acid-type antibiotics. Adv Appl Microbiol 25: 95-146.

Williamson DA, Monecke S, Heffernan H, Ritchie SR, Roberts SA, Upton A, Thomas MG, Fraser JD. 2014. High usage of topical fusidic acid and rapid clonal expansion of fusidic acid-resistant Staphylococcus aureus: A cautionary tale. Clin Infect Dis 59: 1451-1454.

Wilson DN. 2014. Ribosome-targeting antibiotics and mechanisms of bacterial resistance. Nat Rev Microbiol 12: 35-48.

Wolfe CR. 2011. Case report: Treatment of chronic osteomyelitis. Clin Infect Dis 52: S538-S541.

Wullt M, Odenholt I. 2004. A double-blind randomized controlled trial of fusidic acid and metronidazole for treatment of an initial episode of Clostridium difficileassociated diarrhea. J Antimicrob Chemother 54: 211 216.

Zimmerli W, Trampuz A, Ochsner PE. 2004. Prostheticjoint infections. N Engl J Med 351: 1645-1654. 


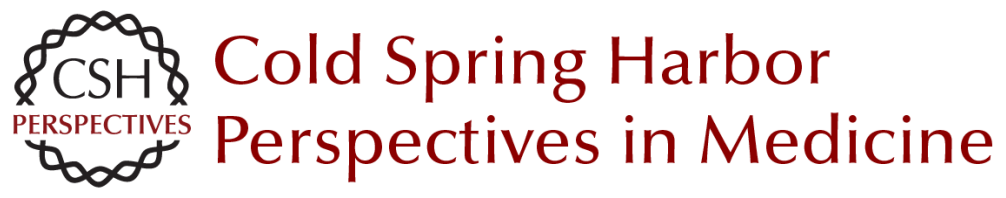

\title{
Fusidic Acid: A Bacterial Elongation Factor Inhibitor for the Oral Treatment of Acute and Chronic Staphylococcal Infections
}

\author{
Prabhavathi Fernandes
}

Cold Spring Harb Perspect Med 2016; doi: 10.1101/cshperspect.a025437

\section{Subject Collection Antibiotics and Antibiotic Resistance}

Fosfomycin: Mechanism and Resistance

Lynn L. Silver

Pleuromutilins: Potent Drugs for Resistant Bugs

--Mode of Action and Resistance

Susanne Paukner and Rosemarie Riedl

Appropriate Targets for Antibacterial Drugs Lynn L. Silver

Lincosamides, Streptogramins, Phenicols, and Pleuromutilins: Mode of Action and Mechanisms of Resistance

Stefan Schwarz, Jianzhong Shen, Kristina Kadlec, et al.

Resistance to Macrolide Antibiotics in Public Health Pathogens

Corey Fyfe, Trudy H. Grossman, Kathy Kerstein, et al.

Bacterial Protein Synthesis as a Target for

Antibiotic Inhibition

Stefan Arenz and Daniel N. Wilson

Antibacterial Antifolates: From Development through Resistance to the Next Generation

Alexavier Estrada, Dennis L. Wright and Amy C. Anderson

Antibacterial Drug Discovery Targeting the Lipopolysaccharide Biosynthetic Enzyme LpxC Alice L. Erwin
The Whys and Wherefores of Antibiotic

Resistance

Cameron R. Strachan and Julian Davies

$\beta$-Lactamases: A Focus on Current Challenges Robert A. Bonomo

Approved Glycopeptide Antibacterial Drugs: Mechanism of Action and Resistance Daina Zeng, Dmitri Debabov, Theresa L. Hartsell, et al.

Mechanism of Action and Resistance to Daptomycin in Staphylococcus aureus and Enterococci

William R. Miller, Arnold S. Bayer and Cesar A. Arias

Polymyxin: Alternative Mechanisms of Action and Resistance

Michael J. Trimble, Patrik Mlynárcik, Milan Kolár, et al.

Topoisomerase Inhibitors: Fluoroquinolone

Mechanisms of Action and Resistance David C. Hooper and George A. Jacoby

$\beta$-Lactams and $\beta$-Lactamase Inhibitors: An

Overview

Karen Bush and Patricia A. Bradford

Rifamycins, Alone and in Combination David M. Rothstein

For additional articles in this collection, see http://perspectivesinmedicine.cshlp.org/cgi/collection/ 